\section{Seasonality, negative life events and social support in a community sample}

\author{
ERIN E. MICHALAK, CLARE WILKINSON, KERENZA HOOD, \\ CHRIS DOWRICK and GREG WILKINSON
}

\section{Background Seasonal affective disorder (SAD) is now a well-described form of depressive disorder. However, relatively little research has focused upon psychosocial factors and SAD.}

\begin{abstract}
Aims To determine the association between demographic/psychosocial factors and increased reported seasonal patterns of mood disorder (seasonality) and SAD in a community sample in the UK.
\end{abstract}

\begin{abstract}
Method A total of 1250 people, aged between 18 and 64 years, randomly selected from a primary care database were screened for SAD. Those above cutoff underwent diagnostic interview and completed several self-report questionnaires. Multivariate analysis was conducted to determine which variables were significantly associated with increased seasonality.
\end{abstract}

\section{Results Four factors (having} experienced more numerous negative life events, having low levels of social support, being a woman and being non-native) were predictive of higher seasonality. Being a woman was predictive of being diagnosed as a case of SAD.

\section{Conclusions A new association has been identified between increased seasonality, negative life events and social support. Future research should assess the psychosocial causes or consequences of SAD while continuing to examine the biology of the condition.}

\section{Declaration of interest G.W. is Editor of the British Journal of Psychiatry. Funding detailed in Acknowledgements.}

Seasonal affective disorder (SAD) is now a well-described form of recurrent major depression characterised by a range of typical and atypical depressive symptoms and a distinct seasonal nature (Rosenthal et al, 1984; Lam \& Levitt, 1999). It is thought to be related to reduced levels of daylight during the winter months, and a significant body of research has now accumulated concerning the biological causes and consequences of the condition. Comparatively little research has focused upon psychosocial factors and SAD. In particular, no research has directly examined the relationship between psychosocial factors, such as negative life events and poor social support, and seasonal depression, although these variables have been found to be associated with increased risk of non-seasonal depression (Brown \& Harris, 1978, 1989; Henderson \& Byrne, 1981).

The present study aimed to assess the association between a range of demographic and psychosocial factors and 'seasonality' (determined by a continuous score on a commonly used screening tool for SAD) and 'caseness' (likelihood of being diagnosed as a case of SAD) in a community sample in the UK.

\section{METHOD}

\section{Background}

The research reported here was conducted in conjunction with the Outcomes of Depression International Network (ODIN) project, designed to assess the prevalence of and risk factors for depression in urban and rural areas within the European Union. Full details of the ODIN project have been published elsewhere (Dowrick et al, 1998, 1999).

\section{Sample frame}

The sample consisted of adults, aged between 18 and 64 years, registered on the North Wales Health Authority's general practice database and residing within the former Glyndwr council district in North Wales.

\section{Case finding}

A two-phase sampling method (Pickles et $a l, 1995)$ was adopted as a research strategy, using a self-rating postal survey to identify potential cases, followed by structured diagnostic interview and more-detailed questionnaires with those participants scoring above cut-off.

Potential cases of SAD were identified using a sub-scale of the Seasonal Patterns Assessment Questionnaire (SPAQ; Rosenthal et al, 1987), a commonly used screening tool for SAD that provides a 'global seasonality score' (GSS) for a given individual. This score ranges from 0 to 24 ; it indicates the degree of change that individuals experience between the seasons in their sleep, mood, weight, appetite, energy and social activity, and requires that they describe whether these changes represent a mild, moderate, marked, severe or disabling problem for them. The traditional cut-off score of 11 or more, with seasonal changes amounting to at least a 'moderate' problem, was applied (Kasper et al, 1989; Rosen et al, 1990). The SPAQ shows reasonable psychometric properties but does tend to produce high false-positive rates compared with clinical diagnosis of SAD. Furthermore, the questionnaire has been criticised for relying upon people's subjective evaluation of seasonal problems and upon their retrospective recall of when depressive episodes occurred. Research has indicated that the reliability of recall of depressive episodes and of seasonal patterns is poor (Wicki et al, 1992; McAllister-Williams et $a l, 1998)$, and that the degree of seasonality is overestimated when recorded retrospectively as opposed to prospectively (Nayyar \& Cochrane, 1996).

Recent negative life events were assessed using the List of Threatening Experiences (LTE), a self-report questionnaire that examines the incidence of 12 categories of negative life events over the previous 6 months (Brugha et al, 1985). The LTE assesses life stressors involving moderate or long-term threat such as illness or injury, death of a close friend or relative, unemployment, financial loss and loss of important relationships. The questionnaire shows acceptable levels of reliability and validity (Brugha \& Cragg, 1990) and a high score has been shown to be associated with 
increased risk of depression (Brugha \& Conroy, 1985). Levels of social support were assessed via a three-item questionnaire called the Oslo 3-Item Social Support Scale (Dalgard, 1996; scale available upon request from Professor Odd Dalgard, e-mail: o.s.dalgard@samfunnsmed.uio.no), which contained questions concerning: number of people the participant reports being close to; concern shown by others; and ease of getting practical help from neighbours. It provides an overall 'social support index' (SSI) score, where higher scores indicate lower levels of social support. Basic demographic questions also were incorporated into the screening package.

The second diagnostic interview stage of assessment was conducted with all consenting participants who scored above cut-off on the SPAQ. Interviews were performed during the winter of 1997-98 by a psychologist (E.E.M.) according to the revised version of the Structured Interview Guide for the Hamilton Depression Rating Scale - Seasonal Affective Disorder Version (SIGH-SAD; Williams et al, 1992). Diagnostic criteria utilised were a minimum score of 15 on the Hamilton Rating Scale for Depression (HRSD), with a score of at least 6 on the supplementary atypical item scale, these being equivalent to those applied in another study of SAD conducted in the UK (Wileman et al, 2001). Diagnosed cases of SAD also met DSM-IV criteria for major depressive episodes with a seasonal (winter) pattern (American Psychiatric Association, 1994).

\section{Ethics}

Ethical approval for the study was obtained from the South Clwyd Ethics Committee in North Wales and all participants provided written informed consent.

\section{Statistics}

Univariate analyses were performed using $\chi^{2}$ for categorical data, Student's $t$-tests for normally distributed continuous data and Mann-Whitney tests for non-normally distributed continuous data. Separate analyses were conducted, examining: factors associated with continuous GSS score (multiple regression); factors associated with being below/above cut-off on the SPAQ (stepwise logistic regression); and factors associated with being diagnosed as a case of SAD (stepwise logistic regression). Regression analyses examined the relationship between these categories and the following variables:

(a) number of negative life events in the past 6 months (mean);

(b) level of social support (SSI score on the Oslo 3-Item Social Support Scale);

(c) marital status (single, married/cohabiting or separated/divorced/widowed);

(d) employment status (in paid employment or other);

(e) occupation type (directly/indirectly employed in agriculture or other);

(f) place of birth (North Wales, elsewhere in UK/outside of UK);

(g) age (as a continuous variable);

(h) gender;

(i) socio-economic status (coded by occupation according to Office of Population, Censuses and Surveys (now the Office for National Statistics) guidelines into three categories: professional, managerial and lower professional; non-manual skilled and skilled manual; and partially skilled and unskilled).

\section{RESULTS}

\section{Response rates}

Screening questionnaires were sent to 1999 people, with a $63 \%(n=1250)$ response rate being obtained. Younger people were significantly less likely to respond to the screening questionnaire than older people $(t=5.7$, d.f. $=1440, P<0.001)$, the mean age of non-responders being 40 years and that of responders being 43 years. Men were significantly less likely to respond than women, with a response rate of $58.6 \% \quad v . \quad 67.4 \% \quad\left(\chi^{2}=16.5, \quad P<0.001\right)$. Sixty-six respondents $(5.3 \%)$ screened positive for SAD according to SPAQ criteria. Of this sample, $55(83 \%)$ agreed to undergo diagnostic interview and 25 were diagnosed with SAD according to the outlined criteria. The results of the epidemiological arm of this study have been reported in detail elsewhere (Michalak et al, 2001).

\section{Multivariate analyses}

The outlined variables were entered into a stepwise multiple regression model to determine their association with GSS, fitted to 1181 cases with complete data. Having experienced more negative life events in the past 6 months, having a poorer social support network, being a woman and being born outside of North Wales were all predictive of higher seasonality scores (Table 1). These variables, in the same order of significance, were also predictive of scoring above cut-off on the SPAQ using a logistic regression model (results not shown). However, only female gender significantly predicted being diagnosed as a case of SAD (odds ratio=3.8, 95\% CI 1.04-13.9).

\section{Relationship between negative life events and increased seasonality}

The association observed between negative life events and increased reported seasonality was surprising and consequently was made the subject of further analysis. Mean GSS score increased significantly as the number of negative life events experienced increased; participants experiencing 0,1 or $\geqslant 2$ negative life events had mean GSS scores of 4.0, 4.9 and 6.4, respectively. Mean number of negative life events experienced by participants scoring above cut-off on the SPAQ were 1.11 (s.d.=1.39), compared with 0.52 (s.d.=0.91) for those below cut-off (Mann-Whitney, $P<0.001$ ). In the SPAQ-positive group, a nonsignificant trend towards increased negative life events in men was apparent (mean 1.42 (s.d.=1.87) $v .0 .98$ (s.d.=1.15)). Number of negative life events experienced was slightly lower for diagnosed cases of SAD (mean 1.0 (s.d.=1.15) for men, 0.85 (s.d. $=0.88)$ for women, NS). In the larger ODIN sample, DSM-IV diagnosed cases of non-seasonal depression reported having experienced a mean number of negative life events of 1.5 (s.d.=1.6) for men and 1.3 $(\mathrm{s.d}=1.4)$ for women (NS).

It was also of interest to know whether people with increased reported seasonality experience more negative life events at a particular time of the year. In order to address this question the responses of two subgroups of participants were analysed. Screening questionnaires for this project were sent out between February and November 1997. The first group consisted of participants who responded in March or April 1997 (who were reporting negative life events that had occurred in the previous 6 months, i.e. October/November through to March/April). The second group consisted of participants who responded in September or October 1997 (who were reporting negative life events that had occurred between April/May and September/ October). Respondents in each group were 
Table I Stepwise multiple regression analysis predicting 'global seasonality score' from demographic and psychosocial variables

\begin{tabular}{lccr}
\hline Variable & Coefficient $(95 \% \mathrm{Cl})$ & Standardised coefficient & $P$ \\
\hline Recent negative life events & $0.73(0.52$ to 0.95$)$ & 0.19 & $>0.00$ I \\
Social support index & $0.31(0.17$ to 0.45$)$ & 0.13 & $>0.00$ I \\
Gender & $-0.88(-1.30$ to -0.48$)$ & -4.6 & 0.00 I \\
Place of birth & $0.57(0.16$ to 0.99$)$ & 0.76 & 0.007 \\
\hline
\end{tabular}

then split into two further subgroups: a 'non-seasonal group' (those with a GSS score of $\leqslant 6$ ) and a 'seasonal group' (those with a GSS score of $\geqslant 8$ ). A GSS score of $\leqslant 6$ has been used previously to define non-seasonal controls (Andrew et al, 2001), whereas a GSS score of $\geqslant 8$ was selected because it represents the bottom cutoff score for inclusion as a case of SAD (Kasper et al, 1989).

Comparison of the number of negative life events between the two time points was conducted using the Mann-Whitney $U$-test. No overall significant differences were apparent between the March/April and the September/October subgroups ( $\mathrm{Ta}$ ble 2). However, the seasonal subgroup experienced significantly more negative life events than the non-seasonal subgroup at both time points. Thus, it appears that people with increased seasonality experience more negative life events throughout the year, and not during one particular season.

\section{DISCUSSION}

We found that four variables (having experienced more negative life events, having low levels of social support, being a woman and being non-native) were predictive of heightened seasonality and SPAQ caseness in this general population sample. However, only gender was predictive of being

Table 2 Negative life events by time of year

\begin{tabular}{lcc}
\hline Subgroup & Life events (mean (s.d.)) & $P^{\prime}$ \\
\hline March/April & & \\
Total $(n=292)$ & $0.54(0.94)$ & $<0.00 I$ \\
Non-seasonal group $(n=204)$ & $0.39(0.64)$ & \\
Seasonal group $(n=63)$ & $0.95(I .53)$ & $0.00 I$ \\
September/October & & \\
Total $(n=303)$ & $0.70(1.12)$ & \\
Non-seasonal group $(n=234)$ & $0.52(0.79)$ & \\
Seasonal group $(n=46)$ & $1.15(I .4 I)$ & \\
\hline
\end{tabular}

I. Mann-Whitney U-test. diagnosed as a case of SAD. The finding that female gender is a risk factor for SAD is not new, and will not be the subject of discussion here. Instead, the following section will focus upon the relationship between negative life events, social support and place of birth, respectively, and seasonality.

\section{Negative life events}

The present study found that having experienced more recent negative life events was predictive of higher seasonality scores, as measured by the SPAQ. Although a large body of research has examined the relationship between negative life events and nonseasonal depression (Brown \& Harris, 1978, 1989; Henderson \& Byrne, 1981), no previous research has directly examined the relationship between seasonality and life events. Some research has been conducted in relation to $\mathrm{SAD}$ and negative life latter can act as a trigger that shifts seasonal depressives from patterns of seasonal depression into patterns of non-seasonal depression (Sakamoto et al, 1995). Other work has indicated that some episodes of seasonal depression may be triggered by anniversary reactions associated with previous traumatic experiences, but these appear to be relatively rare (Beratis et al, 1994, events, where it has been reported that the
1996). However, our study was underpowered to detect an association between negative life events and diagnosed SAD, and further research is required to determine whether such an association exists in clinical populations.

An over-arching question here concerns whether these increased negative life events are a cause or a consequence of increased seasonality. Although the evidence has been controversial (Tennant et al, 1981), it is generally accepted that stressful or negative life events have a causal relationship with non-seasonal depression (Kendler et al, 1999). Although seasonal depression should not be diagnosed in the presence of seasonally recurring life events such as regular winter unemployment, an as yet unidentified causal relationship between negative life events and increased seasonality may exist. Alternatively, heightened seasonality may result in people experiencing more negative life events. For example, a person who is socially impaired as a result of seasonality might be more likely to experience a relationship breakdown. Secondary analysis of the data obtained here indicated that people with increased seasonality in fact experience more negative life events throughout the year. If increased seasonality were to cause life events, we might have expected to see these increased events in the subgroup of people who completed their questionnaires in March/April, but not in the September/October subgroup. The finding that people with seasonality experience more negative life events throughout the year does not provide direct support for either the notion that seasonality causes life events or that life events cause increased seasonality.

Of course, there are other possible explanations for this observed relationship. Personality factors, for example, may have a role to play. Longitudinal research has shown that women with high neuroticism scores report having experienced more negative life events (Fergusson \& Horwood, 1987), and individuals with seasonality have been shown to have heightened levels of neuroticism (Murray et al, 1995). Again, however, one must question in which direction causality runs in this putative relationship between personality factors and life events. As has been pointed out (Young $\&$ Martin, 1981), people with certain personality types may be more likely to be involved in (or indeed create) social environments in which the risks of exposure to life events are increased. Alternatively, 
exposure to life events may modify personality. Finally, individuals who are high in neuroticism could have a tendency to report more negative life events because of their increased sensitivity and responsiveness (Young \& Martin, 1981).

\section{Social support}

The observed relationship between impaired social support and increased reported seasonality is also new. Once again, it must be questioned whether poor social support results in increased seasonality, or whether heightened seasonality results in diminished social support. In the former scenario, low levels of social support could increase the likelihood that an individual will experience (or report) greater seasonal variation in their mood and behaviour. In this sense, a good social support network might be said to be having a 'buffering' effect against seasonal symptoms. Interestingly, other research has indicated that the buffering effect of social support is particularly pronounced in people with high external loci of control, a personality trait that characterises people who are high in seasonality (Dalgard et al, 1995). Alternatively, people who are high in seasonality are likely to be relatively unsociable for a proportion of the year, and may develop poorer social support networks. Further research utilising a larger subject sample is required to determine whether this association between social support and seasonality is also present in patients who are diagnosed with SAD.

\section{Place of birth}

Finally, being non-native to North Wales significantly predicted higher seasonality. The observation that being native to an area is a protective factor for seasonality is not new. A study of psychiatric nurses in Aberdeen, for example, found that $17 \%$ of 'incomers' were SPAQ cases compared with $11 \%$ of those who had lived in Aberdeen for 5 or more years (Eagles et al, 1996). Other research examining seasonality in indigenous White, British Asian and Asian women found that the last group were more susceptible to winter depression (Suhail \& Cochrane, 1997). Studies in a general population sample in Alaska and an out-patient sample in Canada have observed similar trends (Booker \& Hellekson, 1992; Williams \& Schmidt, 1993), although a study of Japanese residents in Stockholm did not

\section{CLINICAL IMPLICATIONS}

Recent negative life events and poor social support networks are associated with increased seasonality of mood disorder.

Female gender is a risk factor for diagnosed seasonal affective disorder (SAD) in community populations.

Further research should focus upon the psychosocial causes and consequences of seasonality and seasonal depression.

\section{LIMITATIONS}

- The sample of people with diagnosed SAD in this study was relatively small.

- Detection of seasonality relied upon the Seasonal Patterns Assessment Questionnaire, which is a subjective, retrospective questionnaire.

- The research was cross-sectional in nature, limiting the inferences that could be made about causality.

ERIN E. MICHALAK, PhD, Division of Mood Disorders, Department of Psychiatry, University of British Columbia, Canada; CLARE WILKINSON, MD, KERENZA HOOD, PhD, Department of General Practice, University of Wales College of Medicine; CHRIS DOWRICK, MD, Department of Primary Care, University of Liverpool; GREG WILKINSON, MD, Department of Psychiatry, University of Liverpool, UK

Correspondence: E. E. Michalak, Division of Mood Disorders, Department of Psychiatry, 2255 Wesbrook Mall, University of British Columbia, Vancouver V6T 2AI, Canada

(First received 2 August 2002, final revision 5 November 2002, accepted 12 December 2002)

find an effect for acclimatisation (Murase et al, 1995). There are several possible explanations for these findings. People who have lived in one place all their lives may be more acclimatised to that area's weather conditions. Alternatively, natives may have superior social support networks, although in the present study both low social support and being non-native were independent predictors of higher seasonality scores. It remains unclear what mediating variables unpin the observed relationship between place of birth and seasonality. However, the fact that this association has been made in several different countries and populations indicates that it is probably a genuine one.

\section{Conclusions}

The present study has served to generate some new evidence concerning psychosocial factors and increased seasonality. In particular, the study has highlighted a new and intriguing relationship between negative life events, poor social support and heightened seasonality. The cross-sectional nature of the research, the small number of diagnosed cases of SAD identified and the fact that the SPAQ is a retrospective, subjectively rated instrument do limit the inferences that can be made on the basis of the data. Nevertheless, the study provides further evidence of the importance of evaluating the role of psychosocial factors in relation to seasonality and SAD in future research.

\section{ACKNOWLEDGEMENTS}

The North Wales arm of the ODIN project was funded by the European Commission Biomed 2 Programme (contract BMH-4-CT96-168I) and the Wales Office of Research and Development (contract RC092)

\section{REFERENCES}

American Psychiatric Association (1994) Diagnostic and Statistical Manual of Mental Disorders (4th edn) (DSM-IV). Washington, DC: American Psychiatric Association.

Andrew, J. E., Wileman, S. M., Howie, F. L., et al (200I) Comparison of consultation rates in primary care attenders with and without seasonal affective disorder. Journal of Affective Disorders, 62, 199-205. 
Beratis, S., Gourzis, P. \& Gabriel, J. (1994) Anniversary reaction as seasonal mood disorder. Psychopathology, 27, 14-18.

_, _ \& _ (1996) Psychological factors in the development of mood disorders with a seasonal pattern. Psychopathology, 29, 331-339.

Booker, J. M. \& Hellekson, C. J. (1992) Prevalence of seasonal affective disorder in Alaska. American Journal of Psychiatry, 149, 1176-1182.

Brown, G. \& Harris, T. (1978) Social Origins of Depression: A Study of Psychiatric Disorder in Women. New York: Free Press.

_ \& _ (1989) Life Events and Illness. New York: Guilford Press.

Brugha, T. S. \& Conroy, R. (1985) Categories of depression: reported life events in a controlled design. British Journal of Psychiatry, 147, 641-646.

_ \& Cragg, D. (1990) The List of Threatening Experiences: the reliability and validity of a brief life events questionnaire. Acta Psychiatrica Scandinavica, 82 $77-81$.

_ , Bebbington, P., Tennant, C., et al (1985) The List of Threatening Experiences: a subset of 12 life event categories with considerable long-term contextual threat. Psychological Medicine, I5, 189-194.

Dalgard, O. (1996) Community health profile: a tool for psychiatric prevention. In Promotion of Mental Health, Volume 5, 1995 (eds D. R. Trent \& C. A. Reed). Aldershot: Avebury Press.

_, Bjork, S. \& Tambs, K. (1995) Social support negative life events and mental health. British Journal of Psychiatry, 166, 29-34

\section{Dowrick, C., Casey, P., Dalgard, O., et al (1998)} Outcomes of Depression International Network (ODIN). Background, methods and field trials. The ODIN Group. British Journal of Psychiatry, 172, 359-363.

—, Vázquez-Barquero, J. L., Wilkinson, G., et al (1999) Organizing ODIN: a case study in European academic co-operation. The ODIN Group. European Psychiatry, 14, 177-181.
Eagles, J. M., Mercer, G., Boshier, A. J., et al (1996) Seasonal affective disorder among psychiatric nurses in Aberdeen. Journal of Affective Disorders, 37, 129-135.

Fergusson, D. M. \& Horwood, L. J. (1987) Vulnerability to life events exposure. Psychological Medicine, I7, 739-749.

Henderson, A. F. \& Byrne, D. G. (1981) Neurosis and the Social Environment. Sydney: Academic Press.

\section{Kasper, S., Wehr, T. A., Bartko, J. J., et al (1989)}

Epidemiological findings of seasonal changes in mood and behavior. A telephone survey of Montgomery

County, Maryland. Archives of General Psychiatry, 46 823-833.

Kendler, K. S., Karkowski, L. M. \& Prescott, C. A (1999) Causal relationship between stressful life events and the onset of major depression. American journal of Psychiatry, 156, 837-84I.

Lam, R. W. \& Levitt, A. J. (1999) Canadian Consensus Guidelines for the Treatment of Seasonal Affective Disorder. Vancouver, BC: Clinical \& Academic Publishing.

McAllister-Williams, R. H., Ferrier, I. N. \& Young, A. H. (1998) Mood and neuropsychological function in depression: the role of corticosteroids and serotonin. Psychological Medicine, 28, 573-584.

Michalak, E. E., Wilkinson, C., Dowrick, C., et al (200I) Seasonal affective disorder: prevalence, detection and current treatment in North Wales. British Journal of Psychiatry, 179, 31-34.

Murase, S., Kitabatake, M., Yamauchi, T., et al (1995) Seasonal mood variation among Japanese residents of Stockholm. Acta Psychiatrica Scandinavica, 92, 5I-55.

Murray, G. W., Hay, D. A. \& Armstrong, S. M. (1995) Personality factors in seasonal affective disorder. Personality and Individual Differences, 19, 613-617.

Nayyar, K. \& Cochrane, R. (1996) Seasonal changes in affective state measured prospectively and retrospectively. British Journal of Psychiatry, 168 627-632.

Pickles, A., Dunn, G. \& Vázquez-Barquero, J. L. (1995) Screening for stratification in two-phase ('twostage') epidemiological surveys. Statistical Methods in Medical Research, 4, 73-89.
Rosen, L. N., Targum, S. D., Terman, M., et al (1990) Prevalence of seasonal affective disorder at four latitudes. Psychiatry Research, 31, 131-144.

Rosenthal, N. E., Sack, D. A., Gillin, J. C., et al (1984) Seasonal affective disorder: a description of the syndrome and preliminary findings with light therapy. Archives of General Psychiatry, 4I, 72-80.

—, Bradt, G. H. \& Wehr, T. A. (1987) Seasonal Pattern Assessment Questionnaire. Bethesda, MD: National Institute of Mental Health.

Sakamoto, K., Nakadaira, S., Kamo, K., et al (1995) A longitudinal follow-up study of seasonal affective disorder. American Journal of Psychiatry, 152, 862-868.

Suhail, K. \& Cochrane, R. (1997) Seasonal changes in affective state in a sample of Asian and white women. Social Psychiatry and Psychiatric Epidemiology, 32 149-157.

Tennant, C., Bebbington, P. \& Hurry, J. (198I) The role of life events in depressive illness: is there a substantial causal relation? Psychological Medicine, II, 379-389.

Wicki, W., Angst, J. \& Merikangas, K. R. (1992) The Zurich Study. XIV. Epidemiology of seasonal depression. European Archives of Psychiatry and Clinical Neuroscience, 24I, 30I-306.

Wileman, S. M., Andrew, J. E., Howie, F. L., et al (200I) Light therapy for seasonal affective disorder in primary care: randomised controlled trial. British Journal of Psychiatry, 178, 311-316.

Williams, J. B., Link, M. J., Rosenthal, N. E., et a (1992) Structured Interview Guide for the Hamilton Depression Rating Scale - Seasonal Affective Disorder Version (SIGH-SAD). New York: New York State Psychiatric Institute.

Williams, R. J. \& Schmidt, G. G. (1993) Frequency of seasonal affective disorder among individuals seeking treatment at a northern Canadian mental health center. Psychiatry Research, 46, 4I-45.

Young, G. C. \& Martin, M. (198I) Processing of information about self by neurotics. British Journal of Clinical Psychology, 20, 205-212. 